\title{
AVALIAÇÃO DO COMPORTAMENTO DE DIFERENTES SISTEMAS VERTICAIS DE VEDAÇÃO SOB O EFEITO DE CHOQUE TÉRMICO
}

\author{
POLETO, GIOVANA \\ Acadêmica de engenharia civil \\ Unisinos \\ RS; Brasil \\ giovanapoleto@hotmail.com
}

LERNER, LUCAS RAFAEL

Acadêmico de engenharia civil Unisinos

RS; Brasil

lucaaslerner@gmail.com

\author{
NICARETTA, TIAGO \\ Engenhero Civil \\ Unisinos \\ RS; Brasil \\ tiago_erthal@yahoo.com.br
}

\section{CHRIST, ROBERTO}

Prof. Dr em engenharia civil

Unisinos

RS; Brasil

rchrist@unisinos.br

\section{TUTIKIAN, BERNARDO FONSECA}

Prof. Dr em engenharia civil

Unisinos

RS; Brasil

bftutikian@unisinos.br

\section{RESUMO}

O choque térmico é um dos principais responsáveis por falhas nos revestimentos argamassados, podendo destacar da fachada ou sofrer outras anomalias que interferem na habitabilidade ou segurança dos usuários de uma edificação. Assim, de forma comparativa, este trabalho analisou a influência da ação do calor e choque térmico no comportamento de revestimentos argamassados, através de ensaio laboratorial de acordo com a NBR 15575-4 (ABNT, 2013). Foram executadas quatro amostras simulando a união entre alvenaria cerâmica e concreto, variando a forma executiva da interface entre os diferentes materiais, e o tipo de argamassa utilizada no revestimento. Os resultados apontaram um comportamento distinto entre as tecnologias construtivas. Notou-se, ainda, que o surgimento de fissuras nos revestimentos, durante o ensaio, está relacionado às características da argamassa de revestimento, principalmente no que diz respeito à resistência mecânica da mesma. Para as amostras sem ligação reforçada da alvenaria com o pilar, a expansão na região central frente a ação do calor foi maior do que as que contavam com a ligação. Por fim, conclui-se por meio do ensaio de resistência da aderência à tração, que a ação do choque térmico teve efeito deletério na resistência da aderência dos revestimentos analisados.

Palavras-chave: Choque térmico. Revestimento argamssado. Durabilidade. Desempenho das Edificações

\begin{abstract}
Thermal shock is one of the main factors responsible for failures in mortar coating, which may detach from the facade or suffer other anomalies that interfere in the habitability or safety of the users of a building. Thus, in a comparative way, this work analyzed the influence of the action of heat and thermal shock on the behavior of mortar coatings, through laboratory testing according to NBR 15575-4 (ABNT, 2013). Four samples were performed simulating the union between ceramic masonry and concrete, varying the executive form of the interface between the different materials, and the type of mortar used in the coating. The results showed a different behavior between construction technologies. It was also noted that the appearance of cracks in the coatings, during the test, is related to the characteristics of the coating mortar, especially with regard to its mechanical strength. For samples without reinforced masonry connection with the column, the expansion in the central region in the action of heat was greater than those that had the connection. Finally, it is concluded through the tensile bond strength test, that the thermal shock action had a deleterious effect on the bond strength of the analyzed coatings.
\end{abstract}

Keywords: Thermal shock. Mortar coating. Durability. Building performance. 


\section{INTRODUÇÃO}

Após a publicação da Norma de Desempenho das Edificações Habitacionais, NBR 15575 (ABNT, 2013), a indústria da contrução civil tem buscado, cada vez mais, materiais e tecnologias afim de atender os requisitos estabelecidos pela referida norma. Especificamente na parte 4, a norma de desempenho trata dos requisitos dos sistemas de vedações verticais internos e externos (SVVIE). Os revestimentos utilizados em sistemas externos podem ser de diversas tipologias, sendo comumente utilizados os compostos de argamassas de revestimento. Grande parte das edificações habitacionais construídas no Brasil tem como característica principal a execução em estruturas de concreto armado e fechamento vertical executado em alvenaria de vedação de tijolos e blocos cerâmicos (TÉCHNE, 2006).

As argamassas de revestimento, segundo Carasek (2010), são empregadas no revestimento de paredes, tetos e muros. É comum receberem acabamentos de pintura, revestimento cerâmico, entre outros. O revestimento de argamassa pode ser constituído de camadas de distintas funções e propriedades, como o chapisco, aplicado sobre a base para uniformizar o substrato quanto à absorção de água e melhorar a aderência, o emboço, aplicado sobre o chapisco, regularizando a cobertura da base, e o reboco, executado sobre o emboço a fim de cobri-lo e possibilitar o recebimento da pintura ou outro revestimento. $\mathrm{O}$ revestimento pode ainda ser composto por camada única de argamassa, aplicada sobre o chapisco tendo a função de emboço e reboco, e támbem constituído por revestimento decorativo monocamada, composto por argamassa industrializada aplicada sobre o chapisco, que tem como função a regularização e decoração.

De acordo com Carasek (2010), os revestimentos argamassados, além de regularizarem o substrato e servirem como bases para acabamentos decorativos, contribuem percentualmente nas funções de um sistema de revestimento como: isolamento térmico e acústico, aproximadamente $30 \%$ e 50\%, respectivamente, estanqueidade à água 70 a $100 \%$, segurança ao fogo e resistência a desgastes e impactos superficiais. A autora ainda aponta que quando executados na face externa da parede de uma edificação, os revestimentos têm papel fundamental na proteção da alvenaria e estrutura às intempéries.

Em relação ao desempenho dos revestimentos de fachadas, Arnoult et al. (1995) mencionam que, pelo fato do Brasil ser um país de clima tropical, as edificações estão sujeitas a mecanismos de degradação intensos como as altas temperaturas, umidade, radiação solar e agentes biológicos.

Segundo Esquivel (2009), embora o uso de revestimentos argamassados seja comum, e já existam diversas pesquisas sobre esta tecnologia, ainda há aspectos pouco estudados, como é o caso da avaliação do seu desempenho e comportamento mecânico. Ainda, de acordo com o autor, para manter o nível de desempenho esperado ao longo da sua vida útil, o revestimento terá que suportar solicitações que surgem desde as primeiras idades como também as que são causadas por agentes de degradação que atuam comumente de forma simultânea.

Em decorrência dessas solicitações em que o revestimento é submetido, este pode vir a apresentar diversas manifestações patológicas, entre elas, o aparecimento de eflorescências na superfície e fissuras, ou até mesmo, em casos mais severos, o desprendimento da base. De acordo com Moscovo (2013), deve-se avaliar, sempre que possível, as condicionantes climáticas, de localização e outras que podem atuar na obra a que se destina a argamassa de revestimento, para poder escolher a tecnologia ideal.

Segundo Oliveira et al. (2014), a reação frente aos sucessivos ciclos de choque térmico nas fachadas, decorrente de altas temperaturas provocadas por radiações solar e brusco resfriamento, provocado por chuvas ou mudança de temperatura, resulta em elevadas tensões nos sistemas de fachadas, principalmente em sistemas leves e de baixa inércia ou em sistemas de múltiplas camadas de materiais não homogêneos. Desse modo, observa-se que para avaliar a durabilidade das fachadas, é indispensável considerar o efeito dos sucessíveis ciclos de choque térmicos. De acordo com o autor, estudar a forma de proceder e as técnicas de ensaios que determinam a reação de um elemento de construção quando exposto aos efeitos do choque térmico é fundamental para concluir sobre sua durabilidade.

As solicitações que afetam o comportamento mecânico dos revestimentos argamassados devem-se a dois fatores. O primeiro é a movimentação da base, em estrutura de concreto ou em alvenaria, quando incompatível com a movimentação do revestimento em argamassa. O segundo fator, deve-se à movimentação provocada pelas condicionantes térmicas, devido à radiação solar, rápida ou sazonal, e as provocadas pelo vento e higroscópicas, que são provocadas pelo ambiente em que o revestimento está submetido (AGENCE QUALITÉ CONSTRUCTION, 1995).

Para Esquivel (2009), a resposta do material frente à ação do choque térmico depende das condições de contorno, pois, no momento em que se restringem as movimentações externas do corpo de prova, o nível de tensões no revestimento aumentará do mesmo modo que a transferência do calor continuará ocorrendo, até que o revestimento atinja o equilíbrio térmico, ou seja, mesma temperatura em todo corpo de prova. Em virtude da aderência entre o revestimento e sua base, há a ocorrência de tensões que solicitarão o revestimento, e no caso dessas solicitações superarem a resistência mecânica do revestimento, pode haver a ocorrência de fissuras ou até mesmo perda total de aderência.

Détriché e Maso (1986) afirmam que os processos de secagem dos revestimentos ocasionam tensões na interface revestimento-substrato, porque a perda de água que ocorre com a cura da argamassa ocasiona redução volumétrica no revestimento, gerando esforços de tração na argamassa, que, se superiores à resistência do revestimento, podem comprometer sua aderência. 
A NBR 13749 (ABNT, 2013) estabelece, como parâmetro de aceitação de revestimentos de argamassa inorgânica com idades iguais ou superiores aos 28 dias, resistência de aderência à tração maior ou igual a 0,3 MPa para revestimentos argamassados em fachadas de edifícios. Os valores da resistência de aderência são obtidos por meio de ensaios de aderência à tração em corpos de prova da camada de revestimento, conforme NBR 13528 (ABNT, 2010). Além de se mensurar a resistência ao arrancamento, outro fator importante é avaliar o tipo de ruptura. Em casos de ruptura no interior da argamassa, chamada de coesiva, os valores são de inferior relevância. Já em casos de ruptura nas interfaces de aderência, os valores são relevantes e devem ser considerados. (CARASEK, 2010).

Conforme Détriché e Maso (1986), as causas que interferem na aderência dos revestimentos são as propriedades da argamassa e de sua composição, bem como as propriedades do elemento base, forma de aplicação do revestimento argamassado e as circunstâncias climáticas durante e após a execução que afetam a cura do revestimento. Segundo Cardoso (2005), as características reológicas da argamassa também influenciam na aderência no momento da aplicação. Segundo Antunes (2005), os defeitos na interface de ligação do revestimento com a base presentes em cada camada de argamassa/substrato é o maior responsável pela perda de aderência dos revestimentos argamassados. Os defeitos segundo o autor, têm como causa a reologia da argamassa e da energia de lançamento desapropriada. Segundo Carasek (1996), a energia de lançamento e a mistura da argamassa têm papel fundamental na aderência dos revestimentos de argamassa. Logo, o estudo do comportamento de revestimentos de argamassa submetidos a sussecivos ciclos de choque térmico se torna importante, ressaltado pela função e importância do sistema em uma edificação. O presente trabalho propõe comparar o desempenho através dos registros de deslocamentos horizontais, falhas e resistência na aderência à tração, de quatro diferentes sistemas de revestimentos aderidos em base composta por alvenaria de blocos cerâmicos e pilar de concreto armado, submetidos à ação do calor e choque térmico aos 28 dias de cura, através de ensaios laboratorais conforme especificações da NBR 15575 (ABNT, 2013).

\section{PROGRAMA EXPERIMENTAL}

\subsection{Amostras}

Para a realização da pesquisa, foram concfecionadas 4 amostras com diferentes tipologias de execução. Todas as amostras foram constituidas por um sistema com um pilar de concreto armado de seção quadrada posicionado no centro das amostras. Na Tabela 1 estão descritos os sistemas, conjuntamente com suas nomenclaturas.

Tabela 1 - Descrição das amostras de ensaio

\begin{tabular}{|c|c|c|c|}
\hline \multirow{2}{*}{ Amostras } & $\begin{array}{c}\text { Face externa } \\
\text { (exposta ao ensaio } \\
\text { de choque térmico) }\end{array}$ & $\begin{array}{l}\text { Face interna (não } \\
\text { exposta ao ensaio de } \\
\text { choque térmico) }\end{array}$ & \multirow{2}{*}{ Reforço interface de base } \\
\hline & $\begin{array}{c}\text { Espessura do } \\
\text { revestimento } \\
\text { argamassado }(\mathrm{mm}) \\
\end{array}$ & $\begin{array}{c}\text { Espessura do } \\
\text { revestimento } \\
\text { argamassado }(\mathrm{mm}) \\
\end{array}$ & \\
\hline $\begin{array}{l}\text { Parede } 1 \\
\quad(\mathrm{P} 1)\end{array}$ & 30 & 20 & $\begin{array}{c}\text { Reforço com barra de aço CA-50 } \\
\text { com diâmetro } 6,3 \text { mm entre camadas } \\
\text { de blocos - 'ferro cabelo' }\end{array}$ \\
\hline $\begin{array}{c}\text { Parede } 2 \\
\quad(\mathrm{P} 2)\end{array}$ & 30 & 20 & $\begin{array}{l}\text { Argamassa de revestimento (face } \\
\text { externa e interna) com adição de } 600 \\
\mathrm{~g} / \mathrm{m}^{3} \text { de fibras de polipropileno }\end{array}$ \\
\hline $\begin{array}{c}\text { Parede } 3 \\
\text { (P3) }\end{array}$ & 30 & 20 & $\begin{array}{l}\text { Reforço com tela de aço carbono } \\
\text { galvanizado, com malha de } 15 \times 15 \\
\text { mm entre camadas de blocos }\end{array}$ \\
\hline $\begin{array}{l}\text { Parede } 4 \\
\quad(\mathrm{P} 4)\end{array}$ & 30 & 20 & $\begin{array}{c}\text { Reforço com tela de aço carbono } \\
\text { galvanizado, com malha de } 25 \mathrm{x} \\
25 \mathrm{~mm} \text { em ambas as faces (face } \\
\text { externa e interna) como ponte de } \\
\text { aderência. }\end{array}$ \\
\hline
\end{tabular}

A argamassa utilizada na construção das amostras foi do tipo industrializada estabilizada, onde o traço utilizado não foi disponibilizado pelo fornecedor. Os blocos utilizados foram de dimnesões 19x19x29, com resistência à compressão de $14 \mathrm{MPa}$.

Nas Figuras 1 e 2 é possível observar um esboço das amostras. 
P1

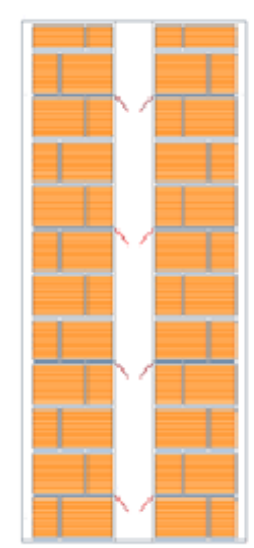

$P 2$

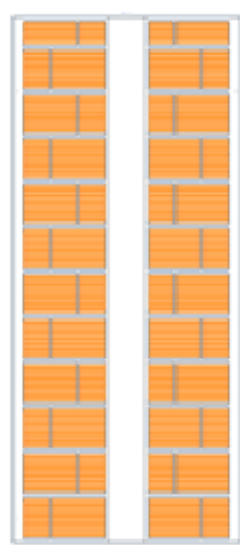

Figura 1 - Amostras P1 e P2
P3

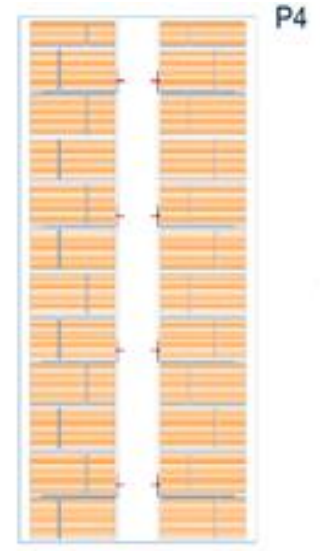

P4

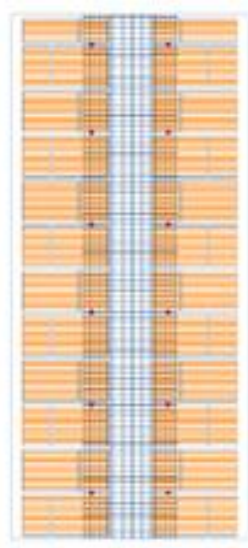

Figura 2 - Amostras P3 e P4

Os sistemas foram executados em pórticos para serem acoplados ao equipamento de ensaio.

\subsection{Método de ensaio}

\subsubsection{Verificação do comportamento do SVVE exposto à ação de calor e choque térmico}

Os ensaios foram realizados conforme o Anexo E da NBR 15575-4 (ABNT, 2013b), o qual prevê o aquecimento da face externa da amostra à temperatura de $(80 \pm 3)^{\circ} \mathrm{C}$ durante $1 \mathrm{~h}$ após a estabilização da referida temperatura e posterior resfriamento da superfície exposta até atingir a temperatura de $(20 \pm 5)^{\circ} \mathrm{C}$. Além disso, o anexo estabelece que as medições dos deslocamentos horizontais devem acontecer, na face oposta à realização do ensaio, aos $45 \mathrm{~min}$ da estabilização da temperatura de aquecimento e imediatamente após o resfriamento da face. Ademais, determina que deve ser registrada a ocorrência de fissuras, trincas, deslocamentos e deteriorações visíveis ao longo de dez ciclos de ensaio. Configura-se um ciclo de ensaio o início do aquecimento da superfície até atingir-se $(80 \pm 3)^{\circ} \mathrm{C}$ e seu posterior resfriamento, após uma hora da estabilização da temperatura, até atingir a temperatura de $(20 \pm 5)^{\circ} \mathrm{C}$. Cada ensaio teve a duração de aproximadamente 15 horas, e foram realizados de $7 \mathrm{em} 7$ dias.

\subsubsection{Medição dos deslocamentos}

A NBR 15575-4 (ABNT, 2013b) estabelece que seja mensurado o deslocamento da amostra no seu centro com um deflectômetro. Todavia, como há um pilar no centro das amostras, pressupõem-se que o deslocamento do revestimento aplicado sobre este pilar é desprezível ou nulo. Por isso, adotou-se uma forma alternativa de medição do deslocamento da amostra em relação ao plano. O deslocamento foi medido através de seis (6) relógios comparadores. Os relógios, foram posicionados na face oposta à face ensaiada, conforme detalhado na Figura 3. As medições foram realizadas em cada ciclo, divididas em duas partes. Uma medição aos $45 \mathrm{~min}$ da estabilização da temperatura superficial em $(80 \pm 3)^{\circ} \mathrm{C}$ e outra imediatamente após o resfriamento da temperatura aos $(20 \pm 5)^{\circ} \mathrm{C}$, conforme NBR 15575-4 (ABNT, 2013b).

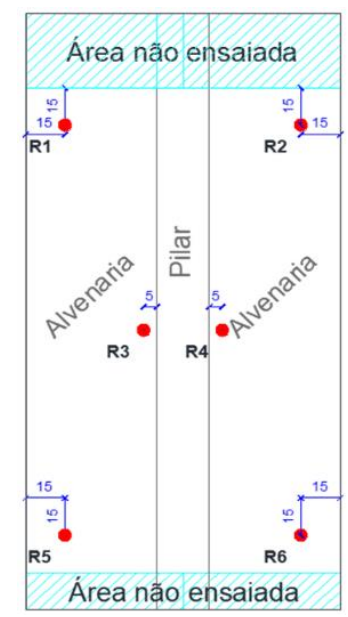


Figura 3 - Posição dos relógios comparadores

2.2.2 Determinação da resistência de aderência à tração

Após a realização dos ensaios de choque térmico, realizou-se os ensaios de determinação da resistência de aderência à tração, conforme preceitos da NBR 13528 (ABNT, 2010). As extrações foram realizadas nas faces expostas à ação de calor e resfriamento e também nas faces não expostas. O número de extrações foi determinado pela quantidade de pastilhas disponíveis para o ensaio, 26 unidades. A NBR 13528 (ABNT, 2010) orienta que um ensaio seja composto por 12 corpos de prova de mesmas características. Com isso, tem-se a necessidade de os ensaios de aderência serem executados em face não exposta ao ensaio de choque térmico e em face exposta ao referido ensaio, tendo assim, 12 corpos de prova para cada situação.

\section{RESULTADOS}

\subsection{Deslocamentos das amostras}

\subsubsection{Deslocamentos da amostra P1}

De acordo com NBR 15575-4 (ABNT, 2013b), o deslocamento horizontal instantâneo no plano perpendicular da amostra não deve ser superior a $\mathrm{h} / 300$, sendo " $h$ " a altura da amostra.

Os deslocamentos obtidos em cada relógio durante a fase de aquecimento e posterior resfriamento estão expostos na Tabela 2, na qual apresentam-se os resultados de cada ciclo do ensaio.

Tabela 2 - Deslocamentos da amostra P1

\begin{tabular}{c|c|c|c|c|c|c|c}
\hline \multirow{2}{*}{$\begin{array}{c}\text { Ciclo } \\
\text { do } \\
\text { ensaio }\end{array}$} & \multirow{2}{*}{ Fase do ensaio } & \multicolumn{3}{|c|}{ Deslocamentos em cada relógio (mm) } \\
\cline { 3 - 8 } & & R1 & R2 & R3 & R4 & R5 & R6 \\
\hline \multirow{2}{*}{1} & Aquecimento & 0,13 & 0,22 & $-0,55$ & $-0,63$ & $-0,32$ & $-0,27$ \\
\cline { 2 - 8 } & Resfriamento & 0,22 & 0,33 & $-0,23$ & $-0,34$ & $-0,27$ & $-0,22$ \\
\hline \multirow{2}{*}{2} & Aquecimento & 0,23 & 0,38 & $-0,19$ & $-0,29$ & $-0,59$ & $-0,54$ \\
\cline { 2 - 8 } & Resfriamento & 0,23 & 0,45 & 0,11 & 0,06 & $-0,57$ & $-0,52$ \\
\hline \multirow{3}{*}{3} & Aquecimento & 0,17 & 0,36 & 0,22 & 0,14 & $-0,04$ & $-0,05$ \\
\cline { 2 - 8 } & Resfriamento & 0,21 & 0,44 & 0,49 & 0,43 & $-0,27$ & $-0,22$ \\
\hline \multirow{3}{*}{4} & Aquecimento & 0,15 & 0,39 & 0,31 & 0,28 & $-0,61$ & $-0,57$ \\
\cline { 2 - 8 } & Resfriamento & 0,20 & 0,46 & 0,65 & 0,63 & $-0,04$ & $-0,03$ \\
\hline \multirow{2}{*}{5} & Aquecimento & 0,16 & 0,46 & 0,45 & 0,42 & $-0,65$ & $-0,64$ \\
\cline { 2 - 8 } & Resfriamento & 0,18 & 0,52 & 0,74 & 0,71 & $-0,62$ & $-0,60$ \\
\hline \multirow{2}{*}{6} & Aquecimento & 0,09 & 0,41 & 0,49 & 0,47 & $-0,04$ & $-0,04$ \\
\cline { 2 - 8 } & Resfriamento & 0,14 & 0,51 & 0,77 & 0,74 & $-0,60$ & $-0,55$ \\
\hline \multirow{2}{*}{7} & Aquecimento & 0,10 & 0,43 & 0,50 & 0,48 & $-0,06$ & $-0,06$ \\
\cline { 2 - 8 } & Resfriamento & 0,14 & 0,52 & 0,74 & 0,74 & $-0,05$ & $-0,04$ \\
\hline \multirow{2}{*}{8} & Aquecimento & 0,12 & 0,44 & 0,59 & 0,56 & $-0,34$ & $-0,30$ \\
\cline { 2 - 8 } & Resfriamento & 0,15 & 0,53 & 0,80 & 0,78 & $-0,31$ & 0,07 \\
\hline & Aquecimento & 0,12 & 0,45 & 0,65 & 0,60 & $-0,35$ & $-0,30$ \\
\hline & Resfriamento & 0,16 & 0,54 & 0,87 & 0,85 & $-0,30$ & $-0,26$ \\
\hline & Resfriamento & 0,16 & 0,55 & 0,36 & 0,35 & $-0,33$ & $-0,28$ \\
\hline
\end{tabular}

A partir dos resultados apresentados na Tabela 2, ilustram-se, na Figura 4, as amplitudes dos deslocamentos máximos da amostra durante o ensaio. 


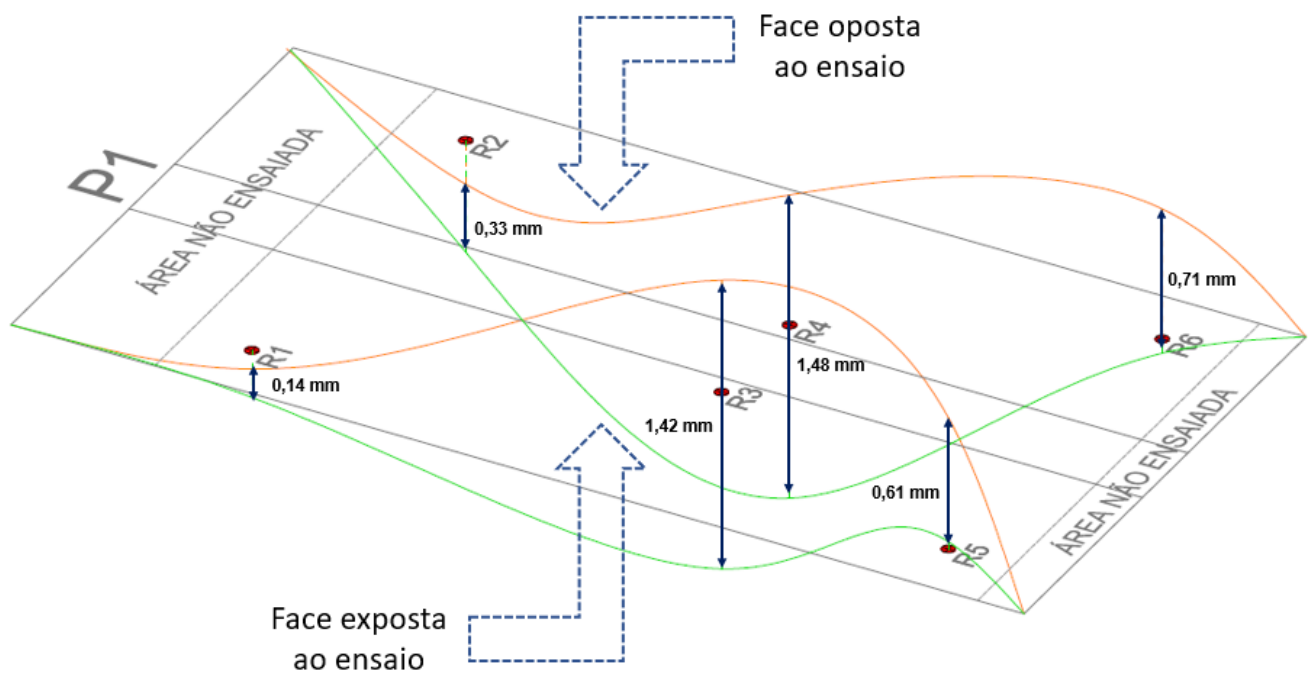

Figura 4 - Projeção dos deslocamentos de cada relógio na amostra P1

A partir das análises realizadas, percebeu-se que, no ciclo 1, a expansão máxima da amostra ocorreu em área central durante a fase de aquecimento. A partir do resfriamento, neste mesmo ciclo, a amostra não obteve expansão semelhante na região central nos ciclos subsequentes. Além disso, a amostra P1 apresentou maior retração nas etapas de resfriamento do que expansão nas etapas de aquecimento. Tal fato resultou em uma amplitude de deslocamento, na região central e inferior, não constatada nas demais amostras.

\subsubsection{Deslocamentos da amostra P2}

Os deslocamentos obtidos são expostos na Tabela 3, na qual apresentam-se os resultados de cada ciclo do ensaio.

Tabela 4 - Deslocamentos obtidos para amostra P2

\begin{tabular}{|c|c|c|c|c|c|c|c|}
\hline \multirow{2}{*}{$\begin{array}{c}\text { Ciclo } \\
\text { do } \\
\text { ensaio }\end{array}$} & \multirow{2}{*}{ Fase do ensaio } & \multicolumn{6}{|c|}{ Deslocamentos em cada relógio (mm) } \\
\hline & & $\mathrm{R} 1$ & $\mathrm{R} 2$ & R3 & $\mathrm{R} 4$ & R5 & R6 \\
\hline \multirow{2}{*}{1} & Aquecimento & $-0,20$ & $-0,18$ & $-0,61$ & $-0,60$ & $-0,26$ & $-0,23$ \\
\hline & Resfriamento & $-0,23$ & $-0,20$ & $-0,54$ & $-0,55$ & $-0,25$ & $-0,25$ \\
\hline \multirow{2}{*}{2} & Aquecimento & $-0,25$ & $-0,23$ & $-0,93$ & $-0,90$ & $-0,39$ & $-0,43$ \\
\hline & Resfriamento & $-0,28$ & $-0,25$ & $-0,85$ & $-0,83$ & $-0,37$ & $-0,42$ \\
\hline \multirow{2}{*}{3} & Aquecimento & $-0,28$ & $-0,26$ & $-0,81$ & $-0,79$ & $-0,35$ & $-0,40$ \\
\hline & Resfriamento & $-0,23$ & $-0,21$ & $-0,62$ & $-0,59$ & $-0,27$ & $-0,24$ \\
\hline \multirow{2}{*}{4} & Aquecimento & $-0,33$ & $-0,32$ & $-0,74$ & $-0,72$ & $-0,32$ & $-0,26$ \\
\hline & Resfriamento & $-0,26$ & $-0,24$ & $-0,53$ & $-0,51$ & $-0,24$ & $-0,21$ \\
\hline \multirow{2}{*}{5} & Aquecimento & $-0,35$ & $-0,35$ & $-0,71$ & $-0,68$ & $-0,31$ & $-0,24$ \\
\hline & Resfriamento & $-0,26$ & $-0,25$ & $-0,48$ & $-0,45$ & $-0,24$ & $-0,20$ \\
\hline \multirow{2}{*}{6} & Aquecimento & $-0,35$ & $-0,34$ & $-0,72$ & $-0,69$ & $-0,32$ & $-0,25$ \\
\hline & Resfriamento & $-0,26$ & $-0,26$ & $-0,56$ & $-0,53$ & $-0,27$ & $-0,21$ \\
\hline \multirow{2}{*}{7} & Aquecimento & $-0,37$ & $-0,41$ & $-0,74$ & $-0,71$ & $-0,33$ & $-0,25$ \\
\hline & Resfriamento & $-0,27$ & $-0,28$ & $-0,53$ & $-0,50$ & $-0,26$ & $-0,21$ \\
\hline \multirow{2}{*}{8} & Aquecimento & $-0,36$ & $-0,41$ & $-0,73$ & $-0,70$ & $-0,33$ & $-0,25$ \\
\hline & Resfriamento & $-0,27$ & $-0,24$ & $-0,55$ & $-0,53$ & $-0,27$ & $-0,21$ \\
\hline \multirow{2}{*}{9} & Aquecimento & $-0,36$ & $-0,35$ & $-0,73$ & $-0,69$ & $-0,33$ & $-0,25$ \\
\hline & Resfriamento & $-0,26$ & $-0,24$ & $-0,58$ & $-0,55$ & $-0,29$ & $-0,23$ \\
\hline \multirow{2}{*}{10} & Aquecimento & $-0,37$ & $-0,38$ & $-0,77$ & $-0,74$ & $-0,35$ & $-0,27$ \\
\hline & Resfriamento & $-0,27$ & $-0,28$ & $-0,62$ & $-0,60$ & $-0,30$ & $-0,24$ \\
\hline
\end{tabular}


A partir dos resultados apresentados na Tabela 3, ilustram-se, na Figura 5, as amplitudes dos deslocamentos máximos da amostra durante o ensaio.

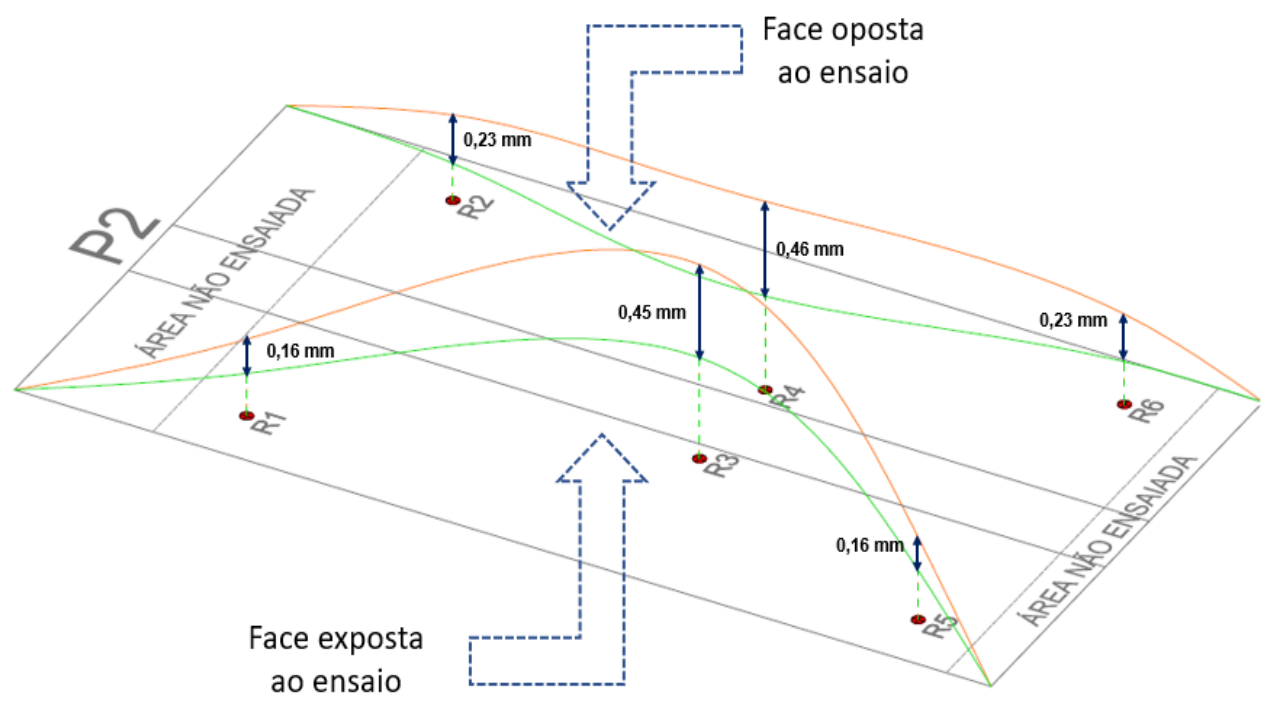

Figura 5 - Projeção dos deslocamentos de cada relógio na amostra P2

Baseado nas análises realizadas, percebeu-se que a expansão máxima da amostra P2 ocorreu em área central, durante a fase de aquecimento no segundo ciclo. Tal expansão foi a maior detectada nas amostras analisadas. Fato este que se justifica pela forma construtiva da parede, a qual não faz uso de elementos de ligação, da alvenaria de vedação ao pilar de concreto. Desta forma, não proporcionou à amostra P2 a redução da esbeltez que ocorreu nas alvenarias que fizeram uso destes elementos.

Conforme Thomaz et al, (2009), a esbeltez da parede de vedação pode ser reduzida empregando elementos de ligação da alvenaria ao pilar, como, por exemplo, os "ferros cabelo" e telas metálicas galvanizadas, ambos utilizados neste trabalho nas amostras P1 e P3, respectivamente.

\subsubsection{Deslocamentos da amostra P3}

Os deslocamentos obtidos em cada relógio durante a fase de aquecimento e posterior resfriamento são expostos na Tabela 4, na qual apresentam-se os resultados de cada ciclo do ensaio.

Tabela 4 - Deslocamentos obtidos para amostra P3

\begin{tabular}{c|c|c|c|c|c|c|c}
\hline \multirow{2}{*}{$\begin{array}{c}\text { Ciclo } \\
\text { do } \\
\text { ensaio }\end{array}$} & \multirow{2}{*}{ Fase do ensaio } & \multicolumn{5}{|c}{ Deslocamentos em cada relógio (mm) } \\
\cline { 3 - 8 } & & R1 & R2 & R3 & R4 & R5 & R6 \\
\hline \multirow{2}{*}{1} & Aquecimento & 0,11 & 0,11 & $-0,32$ & $-0,41$ & 0,32 & 0,34 \\
\cline { 2 - 8 } & Resfriamento & $-0,16$ & $-0,16$ & $-0,32$ & $-0,34$ & 0,32 & 0,36 \\
\hline \multirow{2}{*}{2} & Aquecimento & 0,24 & 0,24 & $-0,53$ & $-0,61$ & 0,36 & 0,32 \\
\cline { 2 - 8 } & Resfriamento & $-0,16$ & $-0,16$ & $-0,50$ & $-0,52$ & 0,36 & 0,36 \\
\hline \multirow{2}{*}{3} & Aquecimento & 0,10 & 0,11 & $-0,47$ & $-0,53$ & 0,43 & 0,48 \\
\cline { 2 - 8 } & Resfriamento & $-0,21$ & $-0,20$ & $-0,43$ & $-0,44$ & 0,42 & 0,41 \\
\hline \multirow{2}{*}{4} & Aquecimento & 0,19 & 0,17 & $-0,50$ & $-0,56$ & 0,43 & 0,47 \\
\cline { 2 - 8 } & Resfriamento & $-0,19$ & $-0,17$ & $-0,45$ & $-0,47$ & 0,43 & 0,41 \\
\hline \multirow{2}{*}{5} & Aquecimento & 0,16 & 0,16 & $-0,45$ & $-0,50$ & 0,47 & 0,50 \\
\cline { 2 - 8 } & Resfriamento & $-0,16$ & $-0,16$ & $-0,44$ & $-0,47$ & 0,42 & 0,42 \\
\hline \multirow{2}{*}{6} & Aquecimento & 0,15 & 0,15 & $-0,43$ & $-0,49$ & 0,49 & 0,51 \\
\cline { 2 - 8 } & Resfriamento & $-0,18$ & $-0,17$ & $-0,40$ & $-0,40$ & 0,44 & 0,47 \\
\hline \multirow{2}{*}{7} & Aquecimento & 0,12 & 0,12 & $-0,40$ & $-0,45$ & 0,49 & 0,53 \\
\cline { 2 - 8 } & Resfriamento & $-0,14$ & $-0,14$ & $-0,40$ & $-0,45$ & 0,47 & 0,50 \\
\hline
\end{tabular}




\section{СВРAT 2020

\begin{tabular}{c|c|c|c|c|c|c|c}
\cline { 2 - 8 } 8 & Aquecimento & 0,18 & 0,18 & $-0,41$ & $-0,47$ & 0,49 & 0,51 \\
\cline { 2 - 8 } & Resfriamento & $-0,12$ & $-0,14$ & $-0,36$ & $-0,38$ & 0,45 & 0,47 \\
\hline \multirow{2}{*}{9} & Aquecimento & 0,19 & 0,18 & $-0,39$ & $-0,45$ & 0,50 & 0,49 \\
\cline { 2 - 8 } & Resfriamento & $-0,07$ & $-0,09$ & $-0,27$ & $-0,30$ & 0,51 & 0,50 \\
\hline \multirow{2}{*}{10} & Aquecimento & 0,21 & 0,23 & $-0,38$ & $-0,44$ & 0,51 & 0,50 \\
\cline { 2 - 8 } & Resfriamento & $-0,10$ & $-0,11$ & $-0,39$ & $-0,40$ & 0,46 & 0,47 \\
\hline
\end{tabular}

A partir dos resultados apresentados na Tabela 4, ilustram-se, na Figura 6, as amplitudes dos deslocamentos máximos da amostra durante o ensaio.

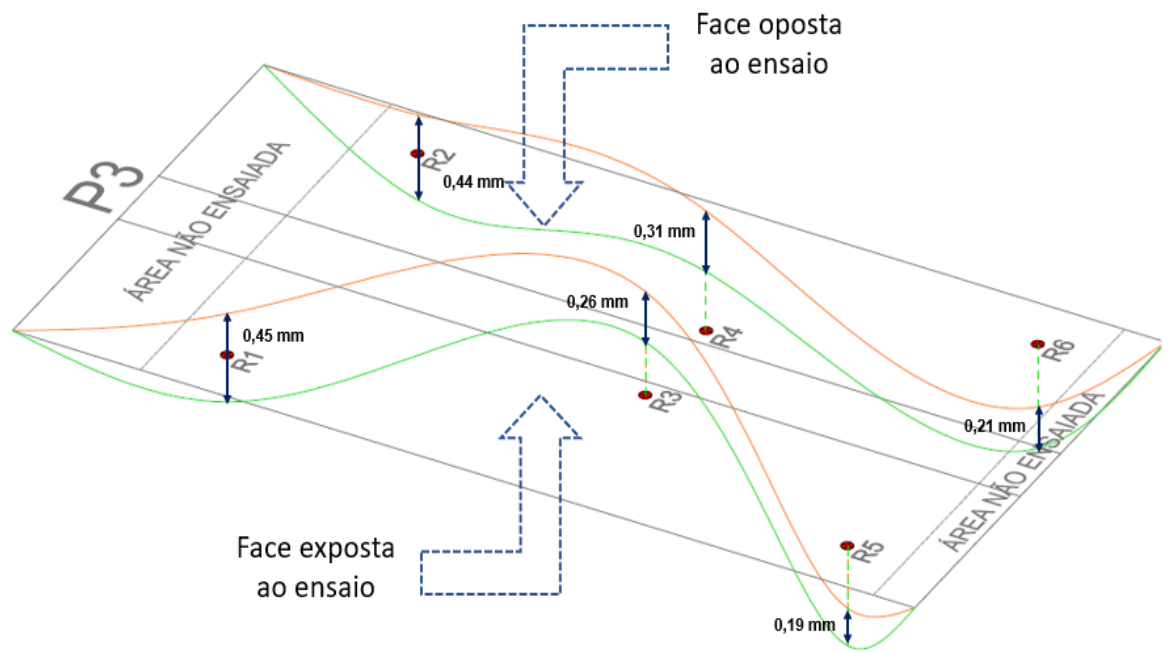

Figura 6 - Projeção dos deslocamentos de cada relógio na amostra P3

Através das análises, observou-se que a maior amplitude dos deslocamentos foi obtida na parte superior da amostra. Tal amplitude pode ter ocorrido pela influência do gradiente térmico diferencial ao longo da amostra, em decorrência da fissuração do revestimento em área superior da face externa da amostra durante o ensaio. Desta forma, no decorrer do ensaio, pode ter ocorrido concentração de umidade na região fissurada, proporcionando infiltrações na amostra e acentuando a movimentação higrotérmica da região.

\subsubsection{Deslocamentos da amostra P4}

Os deslocamentos obtidos em cada relógio durante a fase de aquecimento e posterior resfriamento são expostos na Tabela 5 , na qual apresentam-se os resultados de cada ciclo do ensaio.

Tabela 5 - Deslocamentos obtidos para amostra P4

\begin{tabular}{c|c|c|c|c|c|c|c}
\hline \multirow{2}{*}{$\begin{array}{c}\text { Ciclo } \\
\text { do } \\
\text { ensaio }\end{array}$} & \multirow{2}{*}{ Fase do ensaio } & \multicolumn{6}{|c}{ Deslocamentos em cada relógio (mm) } \\
\cline { 3 - 8 } & & R1 & R2 & R3 & R4 & R5 & R6 \\
\hline \multirow{2}{*}{1} & Aquecimento & $-0,05$ & $-0,05$ & $-0,57$ & $-0,65$ & $-0,21$ & $-0,24$ \\
\cline { 2 - 8 } & Resfriamento & $-0,07$ & $-0,06$ & $-0,45$ & $-0,47$ & $-0,19$ & $-0,23$ \\
\hline \multirow{2}{*}{2} & Aquecimento & $-0,06$ & $-0,05$ & $-0,75$ & $-0,86$ & $-0,30$ & $-0,30$ \\
\cline { 2 - 8 } & Resfriamento & $-0,04$ & $-0,08$ & $-0,62$ & $-0,65$ & $-0,29$ & $-0,30$ \\
\hline \multirow{2}{*}{3} & Aquecimento & $-0,07$ & $-0,07$ & $-0,72$ & $-0,82$ & $-0,27$ & $-0,27$ \\
\cline { 2 - 8 } & Resfriamento & $-0,06$ & $-0,02$ & $-0,50$ & $-0,56$ & $-0,18$ & $-0,19$ \\
\hline \multirow{2}{*}{4} & Aquecimento & $-0,06$ & $-0,06$ & $-0,66$ & $-0,74$ & $-0,21$ & $-0,25$ \\
\cline { 2 - 8 } & Resfriamento & $-0,03$ & $-0,08$ & $-0,51$ & $-0,52$ & $-0,19$ & $-0,22$ \\
\hline \multirow{2}{*}{5} & Aquecimento & $-0,06$ & $-0,06$ & $-0,69$ & $-0,77$ & $-0,25$ & $-0,26$ \\
\hline
\end{tabular}




\begin{tabular}{c|c|c|c|c|c|c|c}
\cline { 3 - 8 } & Resfriamento & $-0,05$ & $-0,08$ & $-0,53$ & $-0,55$ & $-0,23$ & $-0,23$ \\
\hline \multirow{2}{*}{6} & Aquecimento & $-0,05$ & $-0,02$ & $-0,49$ & $-0,56$ & $-0,18$ & $-0,15$ \\
\cline { 2 - 8 } & Resfriamento & $-0,06$ & $-0,05$ & $-0,34$ & $-0,36$ & $-0,11$ & $-0,15$ \\
\hline \multirow{2}{*}{7} & Aquecimento & $-0,04$ & $-0,04$ & $-0,57$ & $-0,65$ & $-0,18$ & $-0,21$ \\
\cline { 2 - 8 } & Resfriamento & $-0,05$ & $-0,04$ & $-0,40$ & $-0,42$ & $-0,14$ & $-0,18$ \\
\hline \multirow{2}{*}{8} & Aquecimento & $-0,05$ & $-0,03$ & $-0,57$ & $-0,66$ & $-0,20$ & $-0,20$ \\
\cline { 2 - 8 } & Resfriamento & $-0,08$ & $-0,01$ & $-0,34$ & $-0,36$ & $-0,11$ & $-0,15$ \\
\hline \multirow{2}{*}{9} & Aquecimento & 0,07 & $-0,01$ & $-0,51$ & $-0,60$ & $-0,21$ & $-0,18$ \\
\cline { 2 - 8 } & Resfriamento & 0,08 & $-0,01$ & $-0,36$ & $-0,38$ & $-0,12$ & $-0,16$ \\
\hline \multirow{2}{*}{10} & Aquecimento & 0,08 & 0,02 & $-0,45$ & $-0,54$ & $-0,11$ & $-0,15$ \\
\cline { 2 - 8 } & Resfriamento & 0,13 & 0,05 & $-0,22$ & $-0,24$ & $-0,09$ & $-0,09$ \\
\hline
\end{tabular}

A partir dos resultados apresentados na Tabela 5, ilustram-se, na Figura 7, as amplitudes dos deslocamentos máximos da amostra durante o ensaio.

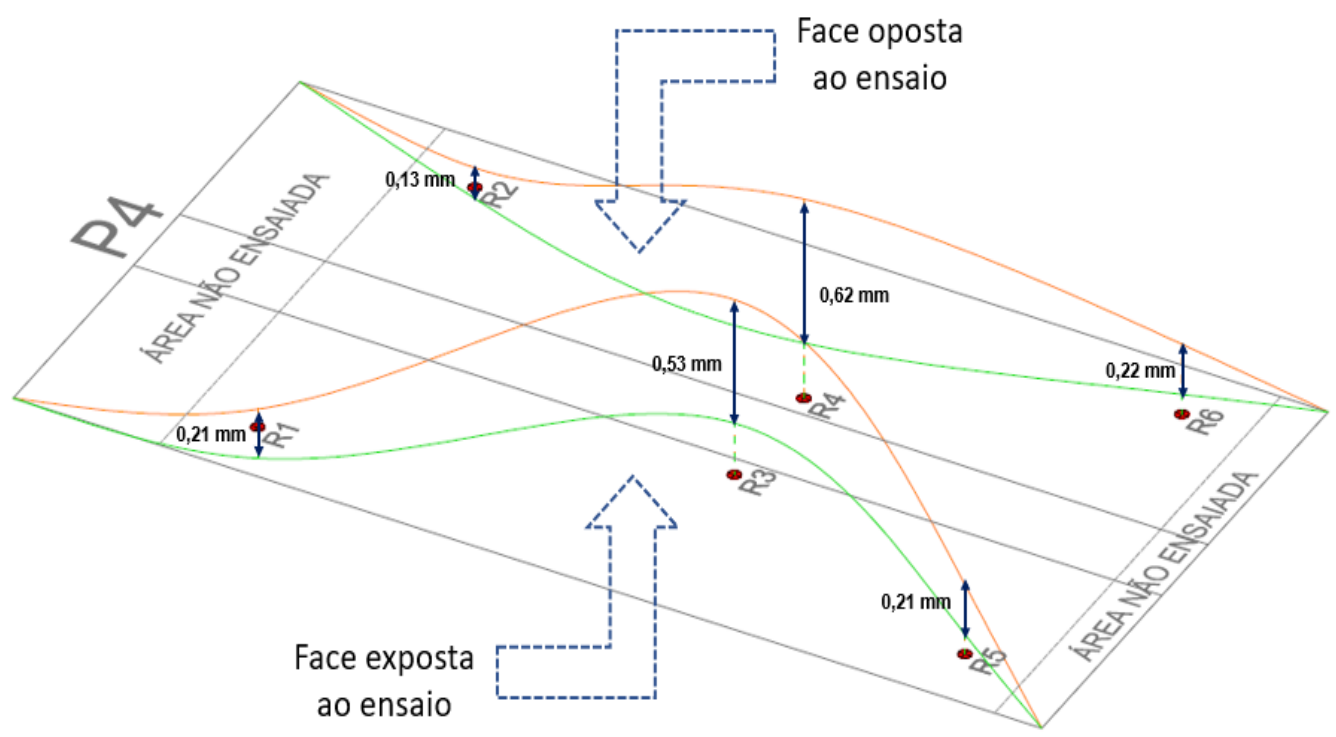

Figura 7 - Projeção dos deslocamentos de cada relógio na amostra 4 (P4)

Por meio das análises, percebeu-se que a expansão máxima da amostra P4 ocorreu em área central, durante a fase de aquecimento no segundo ciclo. Tal expansão foi a segunda maior detectada nas amostras analisadas. Este fato pode ser justificado pela forma construtiva da parede, a qual, assim como a amostra P2, não faz uso de elementos de ligação da alvenaria ao pilar de concreto, portanto, não é beneficiada pelo uso destes elementos na redução da esbeltez da alvenaria. 3.2 Considerações sobre fissuração das amostras

A partir dos resultados apresentados, demonstram-se, na Tabela 6, as extensões das fissuras para melhor avaliação dos resultados.

Tabela 6 - Extensões das fissuras

\begin{tabular}{|c|c|c|c|c|c|c|c|c|}
\hline \multirow{2}{*}{ Região } & \multicolumn{2}{c|}{ P1 } & \multicolumn{2}{c|}{ P2 } & \multicolumn{2}{|c|}{ P3 } & \multicolumn{2}{c|}{ P4 } \\
\cline { 2 - 9 } & $\begin{array}{c}\text { Face } \\
\text { oposta }\end{array}$ & $\begin{array}{c}\text { Face } \\
\text { exposta }\end{array}$ & $\begin{array}{c}\text { Face } \\
\text { oposta }\end{array}$ & $\begin{array}{c}\text { Face } \\
\text { exposta }\end{array}$ & $\begin{array}{c}\text { Face } \\
\text { oposta }\end{array}$ & $\begin{array}{c}\text { Face } \\
\text { exposta }\end{array}$ & $\begin{array}{c}\text { Face } \\
\text { oposta }\end{array}$ & $\begin{array}{c}\text { Face } \\
\text { exposta }\end{array}$ \\
\hline Superior & & 49,2 & 0 & 11,5 & 7 & 49,6 & 37,2 & 25,1 \\
\hline Central & 15,3 & 0 & 35,1 & 0 & 5,8 & 0 & 51,8 & 25,5 \\
\hline Inferior & 4,9 & 0 & 0 & 15,3 & 9,3 & 28 & 26 & 6,7 \\
\hline Subtotal & 20,2 & 49,2 & 35,1 & 26,8 & 22,1 & 77,6 & 115 & 57,3 \\
\hline
\end{tabular}




\begin{tabular}{c|c|c|c|c|c|c|c|c}
$\begin{array}{c}\text { Representatividade } \\
\text { no total }\end{array}$ & $100 \%$ & $100 \%$ & $100 \%$ & $100 \%$ & $9 \%$ & $57 \%$ & $42 \%$ & $100 \%$ \\
\hline
\end{tabular}

\begin{tabular}{c|c|c|c|c|c|c|c|c|}
\hline \multicolumn{1}{|c|}{ Extensão das fissuras pré-existentes ao ensaio $(\mathrm{cm})$} \\
\hline \multirow{2}{*}{ Região } & \multicolumn{2}{|c|}{ P1 } & \multicolumn{2}{c|}{ P2 } & \multicolumn{2}{c|}{ P3 } & \multicolumn{2}{c|}{ P4 } \\
\cline { 2 - 10 } & $\begin{array}{c}\text { Face } \\
\text { oposta }\end{array}$ & $\begin{array}{c}\text { Face } \\
\text { exposta }\end{array}$ & $\begin{array}{c}\text { Face } \\
\text { oposta }\end{array}$ & $\begin{array}{c}\text { Face } \\
\text { exposta }\end{array}$ & $\begin{array}{c}\text { Face } \\
\text { oposta }\end{array}$ & $\begin{array}{c}\text { Face } \\
\text { exposta }\end{array}$ & $\begin{array}{c}\text { Face } \\
\text { oposta }\end{array}$ & $\begin{array}{c}\text { Face } \\
\text { exposta }\end{array}$ \\
\hline Superior & 0 & 0 & 0 & 0 & 55 & 58 & 120 & 0 \\
\hline Central & 0 & 0 & 0 & 0 & 0 & 0 & 0 & 0 \\
\hline Inferior & 0 & 0 & 0 & 0 & 160 & 0 & 42 & 0 \\
\hline Subtotal & 0 & 0 & 0 & 0 & 215 & 58 & 162 & 0 \\
\hline $\begin{array}{c}\text { Representatividade } \\
\text { no total }\end{array}$ & $0 \%$ & $0 \%$ & $0 \%$ & $0 \%$ & $91 \%$ & $43 \%$ & $58 \%$ & $0 \%$ \\
\hline Total & $\mathbf{2 0 , 2}$ & $\mathbf{4 9 , 2}$ & $\mathbf{3 5 , 1}$ & $\mathbf{2 6 , 8}$ & $\mathbf{2 3 7 , 1}$ & $\mathbf{1 3 5 , 6}$ & $\mathbf{2 7 7}$ & $\mathbf{5 7 , 3}$ \\
\hline
\end{tabular}

Desta forma, observa-se que as amostras 3 e 4 apresentaram fissuras predominantemente horizontais, anterior à realização dos ensaios, na face oposta ao ensaio. O mesmo não aconteceu para as amostras P1 e P2. Tais fissuras preexistentes, observadas nas amostras P3 e P4, podem ter ocorrio durante o processo de cura do revestimento em posições ocupadas e durante a execução do revestimento pelas taliscas. Logo, entende-se que a reposição da argamassa das taliscas possa ter comprometido o revestimento nestes trechos, ocasionando o pré-fissuramento durante a cura do revestimento na face interna das amostras $\mathrm{P} 3$ e $\mathrm{P} 4$.

Além disso, observa-se que o grau de fissuração das amostras P1 e P2 foi inferior às amostras P3 e P4, em ambas as faces.

\subsection{Determinação da resistência à tração}

A Tabela 7 apresenta os resultados médios de resistência de aderência à tração obtida em cada parede para área não exposta ao ensaio.

Tabela 7 - Resistência de aderência a tração na face não exposta

\begin{tabular}{c|c|c|c|c|c}
\hline Amostras & $\begin{array}{c}\text { Tensão } \\
\text { requerida }\end{array}$ & $\begin{array}{c}\text { Tensão } \\
\text { Média Ra: } \\
\text { face ñ } \\
\text { exposta } \\
(\mathrm{MPa})\end{array}$ & Umidade & $\begin{array}{c}\text { CP's c/ } \\
\text { tensão } \\
\text { requerida } \\
(\%)\end{array}$ & $\begin{array}{c}\text { Aceitação } \\
\text { ou rejeição } \\
\text { NBR 13528 }\end{array}$ \\
\hline P1 & $>0,30$ & 0,29 & $2,77 \%$ & 5 & Rejeita-se \\
\hline P2 & $>0,30$ & 0,37 & $4,33 \%$ & 7 & Rejeita-se \\
\hline P3 & $>0,30$ & 0,36 & $2,97 \%$ & 8 & Aceita-se \\
\hline P4 & $>0,30$ & 0,47 & $3,64 \%$ & 10 & Aceita-se \\
\hline
\end{tabular}

A partir dos resultados obtidos, observou-se que o ensaio de determinação da resistência de aderência à tração, realizado nas amostras P1 e P2 em área não exposta ao ensaio, apresentou número de corpos de prova com resistência mínima requerida inferior ao determinado pela NBR 13528 (ABNT, 2010). O mesmo não aconteceu para as amostras P3 e P4, nas quais se obteve número desejado de corpos de prova com resistência superior à mínima.

A Tabela 8 apresenta os resultados médios de resistência de aderência à tração obtida em cada parede para face exposta ao ensaio.

Tabela 8 - Resistência de aderência a tração na face exposta

\begin{tabular}{c|c|c|c|c|c}
\hline Amostras & $\begin{array}{c}\text { Tensão } \\
\text { requerida } \\
(\mathrm{MPa})\end{array}$ & $\begin{array}{c}\text { Tensão } \\
\text { Média Ra: } \\
\text { face exposta } \\
(\mathrm{MPa})\end{array}$ & Umidade & $\begin{array}{c}\text { CP's c/ } \\
\text { tensão } \\
\text { requerida } \\
(\%)\end{array}$ & $\begin{array}{c}\text { Aceitação } \\
\text { ou rejeição } \\
\text { NBR 13528 }\end{array}$ \\
\hline P1 & $>0,30$ & 0,25 & $3,17 \%$ & 4 & Rejeita-se \\
\hline P2 & $>0,30$ & 0,35 & $5,60 \%$ & 6 & Rejeita-se \\
\hline P3 & $>0,30$ & 0,29 & $4,6 \%$ & 5 & Rejeita-se \\
\hline P4 & $>0,30$ & 0,40 & $3,64 \%$ & 8 & Aceita-se \\
\hline
\end{tabular}


A partir dos resultados obtidos nos ensaios de DRAT realizados em área exposta ao ensaio, comparando-os com os ensaios realizados em área não exposta, observou-se um declínio da tensão média na resistência de aderência à tração para as quatro amostras, assim como do número de corpos de prova que atenderam a resistência mínima requerida.

A partir dos resultados obtidos, concluiu-se que o efeito de sucessivos ciclos de choque térmico provocou a redução da resistência de aderência à tração dos revestimentos ensaiados. Tal conclusão também foi evidenciada por Esquivel (2009).

\section{CONCLUSÕES}

Com base nos resultados constatados, concluiu-se que as amostras apresentaram diferentes deslocamentos de acordo com a tecnologia construtiva adotada. Para as amostras sem ligação reforçada da alvenaria com o pilar, a expansão na região central frente a ação do calor foi maior do que as que contavam com a ligação. Tal comportamento pode ser atribuído à esbeltez da amostra. Desta forma, quanto maior a esbeltez, maior serão os deslocamentos apresentados quanto à ação ao calor.

É importante salientar que as amostras P3 e P4 apresentaram elevada quantidade de fissuras pré-existentes à realização dos ensaios de choque térmico. Desta forma, conclui-se que tal fato possa ter afetado os resultados obtidos na avaliação das fissuras apresentadas durante os ciclos de ensaio de calor e choque térmico nas referidas amostras.

Quanto ao atendimento dos critérios estabelecidos na NBR 15575 (ABNT, 2013b) para o ensaio, concluiu-se que as quatro amostras ensaiadas não atenderam por completo os critérios estabelecidos na referida norma, a qual trata e degradações durante o ensaio.

Ademais, conclui-se que os ensaios de choque térmico têm ação deletéria na resistência de aderência à tração dos revestimentos analisados. Entretanto, são necessários mais estudos para comprovar as reais causas da perda de resistência, uma vez que não se observou relação entre as manifestações apresentadas e a perda de aderência frente ao ensaio de choque térmico. 


\section{REFERÊNCIAS}

AGENCE QUALITÉ CONSTRUCTION. L'étanchéité des façades 1: exigences et moyens.72p. Paris: EG, França, 1995.

ANTUNES, R. P. Influência da reologia e da energia de impacto na resistência de aderência de revestimentos de argamassa. Escola Politécnica, Universidade de São Paulo, 2005.

ARNOUlT, J.; KREMP, V.; \& MUSEMBI, M. Proceeding of the Pan-African Conference on the Preservation and Conservation of Library and Archival Materials. Headquarters: University of Virginia, 1995.

ASSOCIAÇÃO BRASILEIRA DE NORMAS TÉCNICAS. NBR 15575-4: Edificações habitacionais - DesempenhoParte 4: Requisitos para os sistemas de vedações verticais internas e externas - SVVIE. Rio de Janeiro, 2013.

ASSOCIAÇÃO BRASILEIRA DE NORMAS TÉCNICAS. NBR 13749: Revestimento de paredes e tetos de argamassas inorgânicas. Rio de Janeiro, 2013.

ASSOCIAÇÃO BRASILEIRA DE NORMAS TÉCNICAS. NBR 13528: Revestimento de paredes e tetos de argamassas inorgânicas - Determinação da resistência de aderência à tração. Rio de Janeiro, 2010.

CARASEK, H. Argmassas, Materiais de Construção Civil e Engenharia de Materiais. São Paulo: IBRACON, 2010.

CARDOSO, F. P. Caracterização reológica de argamassas através do método squeeze-flow. Simpósio Brasileiro de Tecnologia de Argamassas, (pp. 121-143). Florianópolis, 2005.

DÉTRICHÉ, C.; MASO, J. Cement and Concrete Research: Differential hydration in rendering mortars, 16, pp. 429-439, 1986.

ESQUIVEL, T. Avaliação da Influência do Choque Térmico na Aderência dos Revestimentos de Argamassa. Tese Doutorado em Engenharia Civil, p. 262, 2009.

MOSCOVO, Y. F. Estudo numérico e experimental das tensões atuantes na argamassa colante de fachadas de edificações sob ação da fadiga termo-mecânica. Publicação E. DM - 008 A/13, p. 142, 2013

OLIVEIRA, L. A.; FONTENELLE, J. H.; MITIDIERI FILHO, C. V. Durabilidade de fachadas: método de ensaio para verificação da resistência à ação de calor e choque térmico. Revista Ambiente Construído, 53-67, 2014.

TÉCHNE. Alvenaria racionaliza. Disponível em: < http://techne.pini.com.br/engenharia-civil/112/artigo285542-1.aspx >. Acesso em: 19 out. 2019.

THOMAS, E.; MITIDIERI FILHO, C. V.; CLETO, F. D.; CARDOSO, F. F. Alvenaria de vedação em blocos cerâmicos. Código de práticas nº 1. São Paulo, Brasil: IPT, 2009. 